\title{
Tailoring carbon nanotube surfaces with glyconanorings: new bionanomaterials with specific lectin affinity $\dagger$
}

\author{
Noureddine Khiar, ${ }^{a}$ Manuel Pernia Leal, ${ }^{a}$ Rachid Baati, ${ }^{* b}$ Christine Ruhlmann, ${ }^{c}$ \\ Charles Mioskowski, $\ddagger^{b}$ Patrick Schultz ${ }^{c}$ and Inmaculada Fernández ${ }^{d}$
}

Received (in Cambridge, UK) 9th March 2009, Accepted 1st May 2009

First published as an Advance Article on the web 2nd June 2009

DOI: $10.1039 / b 904717 d$

Remarkably stable, water-soluble glyconanoring-coated SWCNTs were prepared by self organization and photopolymerization of neutral diacetylene-based glycolipids on the nanotube surface; the nanoconstructs are able to engage in specific ligand-lectin interactions in a similar way to glycoconjugates on cell membranes.

Endowed with unique size, shape and physical properties, single wall carbon nanotubes (SWCNTs) are currently being actively investigated as a vehicle for the in vivo smart delivery of biologically relevant molecules, as nanometric sensors, and potentially, for cancer treatment. ${ }^{1}$ Interestingly, recent investigations, including an in vivo pilot study, have concluded that conveniently functionalized water-soluble SWCNTs are non-toxic. ${ }^{2}$ Therefore, the development of efficient strategies for the construction of water-soluble, biocompatible CNTs is a challenge of paramount importance. ${ }^{3,4}$ Owing to their high surface area, bioengineered CNTs can be used to expose a large number of biomolecules, in a manner that is similar to the species involved in those critical biological processes that favour multivalent ligand-receptor interactions. ${ }^{5}$ A paradigmatic example of such events are those mediated by carbohydrate-protein interactions, ${ }^{4}$ which include cell adhesion, inflammation, tumour cell metastasis, and pathogenic infections. ${ }^{6}$ Building on our interest in the synthesis of CNT-based bionanomaterials, ${ }^{7}$ herein, we report a new bottom-up approach for the preparation of remarkably stable water-soluble SWCNT-carbohydrate nanohybrids with a nanoabacus topology and with specific lectin affinity.

Our rationally designed approach to the desired glyconanoringcoated SWCNTs, Fig. 1, is based on the previously reported self organization around carbon nanotube surfaces of charged anionic surfactants, ${ }^{7 a, 8}$ and on the known selective and

\footnotetext{
${ }^{a}$ Instituto de Investigaciones Quimicas, C.S.I.C-Universidad de Sevilla, c/. Américo Vespucio, 49, Isla de la Cartuja, 41092 Sevilla, Spain.E-mail: khiar@iiq.csic.es; Fax: + 3495 44600565; Tel: + 34954489559

${ }^{b}$ Université de Strasbourg, Faculté de Pharmacie CNRS UMR 7199 Laboratoire de Chimie des Systèmes Fonctionnels, 74, route du Rhin, 67401 Illkirch-Graffenstaden, France

E-mail: baati@bioorga.u-strasbg.fr

c Institut de Génétique et de Biologie Moléculaire et Cellulaire. CNRS/INSERM/ULP, 1 rue Laurent Fries, BP163, F-67404 Illkirch Cedex, France

${ }^{d}$ Departamento de Química Orgánica y Farmacéutica, Facultad de Farmacia, Universidad de Sevilla, 41012 Sevilla, Spain

$\dagger$ Electronic Supplementary Information (ESI) available: Experimental procedures, lectin binding assays, NMR, IR and Raman spectroscopies and additional TEM images. See DOI: $10.1039 / \mathrm{b} 904717 \mathrm{~d}$

$\ddagger$ Deceased. Dedicated to the memory of Dr Charles Mioskowski.
}

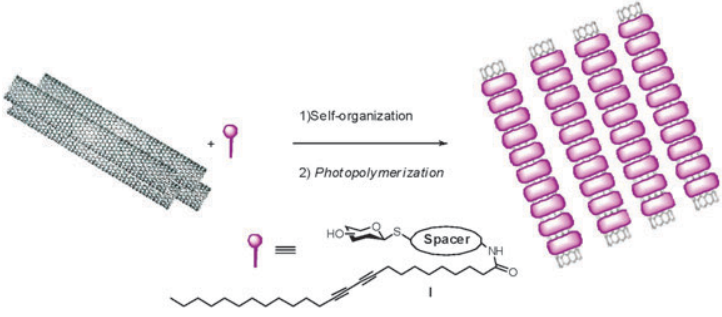

Fig. 1 Overview of the glyconanoring strategy.

smooth photopolymerization of diacetylene-based glycolipids. ${ }^{9}$ Compared to other amphiphiles, glycolipids are characterized by a complexity of interactions among the sugar groups, which add finer details to the hydrophilic-hydrophobic balance governing their self assembly. ${ }^{10}$ Thus, to tailor the properties of the sugar-based biosurfactant for the desired self organization on the nanotube, a diacetylene-based neoglycolipid I was designed, which exhibits a 25 carbon-based hydrophobic tail for an efficient van der Waals interaction with the CNT, with a variable spacer and sugar group for fine tuning of the hydrophilic-hydrophobic balance of the molecule. Neutral detergents 7-11 used in this study (Scheme 1), were obtained by a new, convergent, and modular strategy, starting from (2-aminoethyl)-per-O-acetylated-1-thio-glycosides 1, 2, and 3, for which a one step approach has been developed (see ESI $\dagger$ ).

Sonication of SWCNTs in the presence of a homogeneous aqueous solution of Lac-7 afforded unstable aggregates as evidenced by rapid sedimentation of the carbon nanotubes in the medium. This result reveals that lipid Lac-7 is unable to self organize on the nanotube side-wall, most probably due to its intrinsically unfavorable hydrophilic-hydrophobic balance.

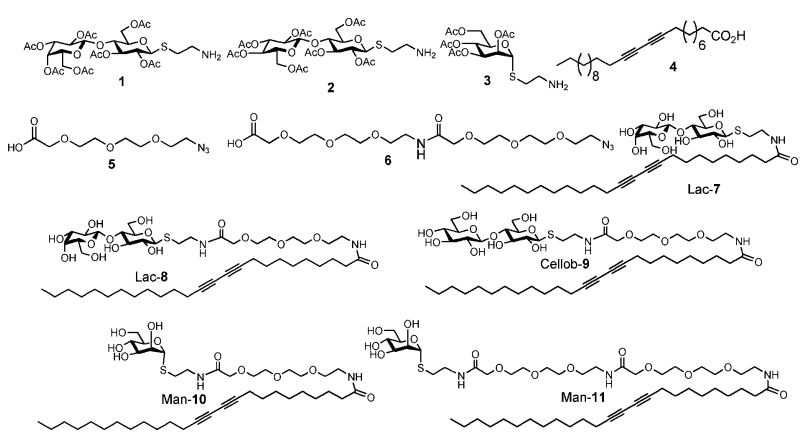

Scheme 1 Structures of (2-aminoethyl)-per-O-acetylated-1-thio-lactoside 1, cellobioside $\mathbf{2}$, and mannoside $\mathbf{3}$, the bifunctional spacers $\mathbf{5 - 6}$, and the diacetylenic acid $\mathbf{4}$ used for the synthesis of diacetylene-based Lac-7, Lac-8, Cellob-9, Man-10, and Man-11. 

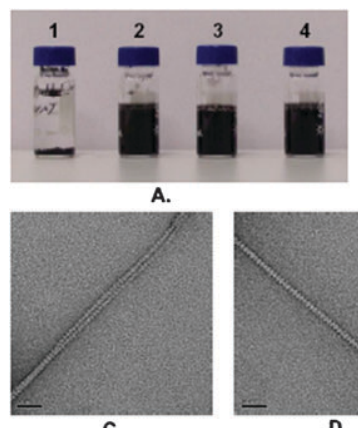

c.
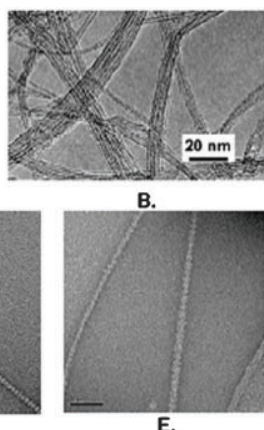

D.
E.

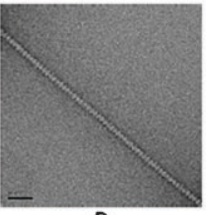

Fig. 2 (A) Photographs of vials containing aqueous solution of: 1. SWCNTs, 2. SWCNT-Lac-8, 3. SWCNT-Cellob-9, 4. SWCNTsMan-11. TEM images of the nanoconstructs negatively charged with uranyl acetate: (B) as produced SWCNTs, (C) SWCNT-Lac-8, (D) SWCNT-Cellob-9, (E) SWCNT-Man-11.

In order to validate this hypothesis, the more hydrophilic lactose based surfactant Lac-8 was synthesized. This has been achieved by the incorporation of the bifunctional ethylene glycol derived spacer 5, obtained from tetraethylene glycol in three steps (see ESI $\dagger$ ) via amide bond linkage, to the (2-aminoethyl)-2,2',3,3',4',6,6'-hepta- $O$-acetyl-1-thio- $\beta$-lactoside $\mathbf{1}$. After Staudinger azide reduction, a synthetic route similar to that used for Lac-7, afforded glycolipid Lac-8 in good yield. Consequently, by simply mixing the neutral lipid Lac-8 with CNT in water without any additive, followed by sonication for 30 min, a black solution which remained stable for months was obtained (Fig. 2A, vial 2). A similar stable black suspension was obtained when glycolipid Cellob-9 derived from cellobiose disaccharide was used with the same SWCNTs (Fig. 2A, vial 3). These results show that an increase in the hydrophilic-hydrophobic balance of the glycolipids, by adding a poly(ethylene glycol) (PEG) chain, is crucial for the functionalization of SWCNTs and the formation of stable nanoconstructs in pure aqueous conditions. This observation is corroborated by the fact that: (i) a decrease of the hydrophilichydrophobic balance of the surfactant by using a monosaccharide such as in Man-10, gave exclusively unstable aggregates that precipitated quickly in water, and (ii) the use of neoglycolipid Man-11 with the same sugar epitope but a longer hydrophilic spacer $\mathbf{6}$ allows the remarkable solubilization and functionalization of carbon nanotubes in pure water. The macroscopic observation of a stable black suspension is a result of the change in the native hydrophobicity of the nanotube side wall, becoming more hydrophilic, due to the functionalization of the SWCNT's surface with glycolipids and the exposure of the sugar epitopes to the polar water phase. The characterization of SWCNT-neoglycolipid nanoconstructs was carried out by transmission electron microscopy (TEM), and nuclear magnetic resonance (NMR), infra-red (IR) and Raman spectroscopies (see ESI $\dagger$ ).

TEM images of native SWCNTs and SWCNTs-coated with neoglycolipid Lac-8 are given in Fig. 2B and 2C, respectively. As a consequence of the hydrophobic interactions, van der Waals forces, and $\pi$-stacking among individual nanotubes, as produced SWCNTs usually exist as dense bundles or ropes that are deeply interconnected, Fig. 2B. ${ }^{11}$ Quite remarkably, a simple functionalization with neoglycolipids Lac-8, Cellob-9

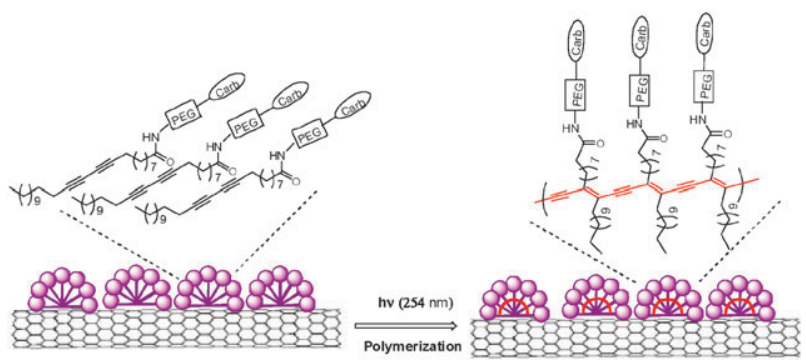

Fig. 3 Formation of SWCNTs coated with polydiacetylene-based glyconanorings in pure water.

or Man-11 in pure water and strictly neutral conditions, allowed the CNTs packages to exfoliate producing small mainly individual sugar-coated nanotubes, as evidenced by TEM analysis (Fig. 2C, D and E). Interestingly, the TEM images show that the surface of the nanotube is completely covered by striations of hemi-micelles, that can slide on the nanotube in a similar way to beads on a single wire in an antique abacus. Similar associations were previously reported for charged and zwitterionic amphiphilic lipids, ${ }^{7,8}$ but as far as we know this is the first time where such organization is reported for a neutral, non-ionic surfactant in pure water. ${ }^{12}$ While up to three mechanisms were proposed to explain the dispersion of CNTs with surfactants, ${ }^{13}$ the observed periodic striations suggest that the microscopic binding mode is the half cylinder mode. ${ }^{7 a}$ Interestingly, under such supramolecular organization it is well documented that diacetylene lipids undergo efficient and clean polymerization via a 1,4-addition reaction to form alternating ene-yne polymer chains upon light irradiation at $254 \mathrm{~nm},{ }^{9}$ affording strong polymerized glyconanorings around the surface nanotubes as shown in Fig. 3. ${ }^{14}$

After sonication of SWCNTs in the presence of aqueous solution of Lac-8 as before, the mixture was then irradiated by a laboratory UV lamp $(254 \mathrm{~nm})$ for $12 \mathrm{~h}$ in order to promote the polymerization of the diyne functional groups around the nanotube. The high stability of the polymerized glyconanorings was ascertained by comparison with that of the non-polymerized counterpart nanohybrids. While the latter precipitated after three months the former ones remained stable for at least six months. Additionally, the stable suspension of CNTs functionalized with polymerized glyconanorings remained unchanged after washing with methanol, heating in water at $80{ }^{\circ} \mathrm{C}$ for one week, and when diluted in Hepes buffer ( $20 \mathrm{mM}$ at pH 7.5) - in contrast with the non-polymerized CNT-glycolipid nanoconstructs and to most of the surfactant-based CNT-solubilization systems developed so far (see ESI $\dagger$ ). These results indicate that the SWCNTs are coated with polymerized polydiacetylene-based glyconanorings (PDA-GNR), forming stable, water-soluble multicomposites namely SWCNT-PDA-GNR-Lac-8. It is worth mentioning that this feature extends the utility of our bionanomaterials, since polydiacetylene-tethered biomolecules have recently received a great deal of attention as biosensors, due to their unique properties upon external stimulation. ${ }^{9 b}$

A central issue of this study was to demonstrate the ability of such sugar epitope-bearing bionanomaterials to engage in specific interactions with protein receptors. Theoretically, each polymerized nanoring on the nanotube surface is surrounded by a large number of sugar epitopes, much like the glycocalyx 


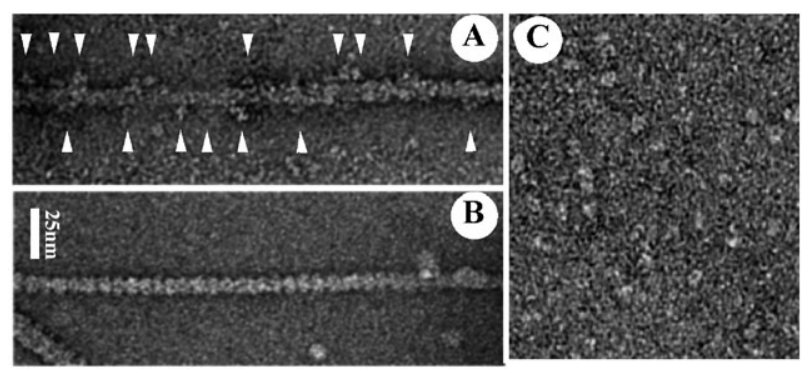

Fig. 4 TEM characterization of the specificity acquired by the aggregates toward specific receptors. (A) Interaction of PNA with SWCNT-Lac-8. The abacus like geometry is lost as the striations are covered by lectin molecules (white arrows). (B) Interaction of PNA with SWCNT-Cellob-9. There is no specific interaction and the characteristic striations are still observed. (C) TEM image of purified PNA lectin alone.

at the cell membrane surface, and can act as ligands for specific receptors. Therefore the SWCNT-PDA-GNR-Lac-8 exhibiting lactose residues on the nanotube's surface could be recognized by a lactose-specific receptor such as Peanut agglutinin (PNA) from Arachis hypogaea. ${ }^{15}$ In order to confirm this hypothesis, we incubated SWCNT-PDA-GNR-Lac-8, with PNA in Hepes buffer at $\mathrm{pH} 7.4$ for 1 hour, and the result of the interaction was characterized by TEM. As can be seen from Fig. 4A, the abacus-like geometry was lost and the characteristic striations could not be observed. The lectins covered extensively the functionalized nanotubes whose surface becomes fuzzy and from which individual lectin molecules can be found to stick out (Fig. 4A, white arrows). Where they could be clearly delineated at the edges of the tubes, the sizes of the particles attached to the Lac-8-coated SWCNT were measured. A value of $70 \AA$ was obtained ( $\sigma=8 \AA, \nu=13)$, which is consistent with the size of the $110 \mathrm{kDa}$ PNA homotetramer for which a hydrodynamic radius of $39 \AA$ was determined by ultracentrifugation analysis and dynamic light scattering measurements. ${ }^{16}$ Additionally, the size of the attached particles, Fig. 4A is identical to the size of purified lectin macromolecules observed by electron microscopy in the absence of nanotubes (see Fig. 4C). As a control experiment to demonstrate that the absence of the striations formed by the glyconanorings is a consequence of the specific interaction between the lectin and the nanohybrid, we performed the same reaction between the lectin and the glyconanohybrid SWCNT-PDA-GNR-Cellob-9, exposing the cellobiose glycoligand which is not recognized by PNA. In this case the characteristic abacus-like geometry can still be observed (Fig. 4B), as a consequence of the absence of specific interactions between PNA lectin and SWCNT-PDA-GNR-Cellob-9. These results demonstrate that SWCNTs coated with glyconanorings can engage in specific molecular recognition with a protein receptor and preclude non-specific protein binding.

The specific interactions with other biologically relevant species such as cells, bacteria, and toxins, as well as studies devoted to the removal of these fascinating polymerized glyconanorings (GNR) from the nanotubes surface, their recovery and further use, are under investigation in our laboratories.

This work was supported by the DGICyT (grant No. CTQ2006-15515-CO2-01 and CTQ2007-61185), the Junta de Andalucía (grant P06-FQM-01852 and P07-FQM-2774), the
CNRS (France) and CSIC (Egide Picasso 09543XA and PICS Program 2008).

\section{Notes and references}

1 (a) D. Pantarotto, J. Briand, M. Prato and A. Bianco, Chem. Commun., 2004, 16; (b) N. K. W. Kam, T. C. Jessop, P. A. Wender and H. J. Dai, J. Am. Chem. Soc., 2004, 126, 6850; (c) N. K. W. Kam, Z. Liu and H. J. Dai, J. Am. Chem. Soc., 2005, 127, 12492; (d) D. Pantarotto, R. Singh, D. McCarthy, M. Erhardt, J.-P. Briand, M. Prato, K. Kostarelos and A. Bianco, Angew. Chem., Int. Ed., 2004, 43, 5242; (e) N. K. W. Kam, Z. Liu and H. J. Dai, J. Am. Chem. Soc., 2005, 127, 6021; $(f)$ S. Lin, G. Keskar, Y. Wu, X. Wang, A. S. Mount, S. J. Klaine, J. M. Moore, A. M. Rao and P. C. Ke, Appl. Phys. Lett., 2006, 89, 143118; $(g)$ N. K. W. Kam, M. O'Connell, J. A. Wisdom and H. J. Dai, Proc. Natl. Acad. Sci. U. S. A., 2005, 102, 11600.

2 (a) R. Singh, D. Pantarotto, L. Lacerda, G. Pastorin, C. Klump, M. Prato, K. Kostarelos and A. Bianco, Proc. Natl. Acad. Sci. U. S. A., 2006, 103, 3357; (b) M. L. Schipper, N. NakayamaRatchford, C. Davis, N. K. W. Kam, P. Chu, Z. Liu, X. Sun and H. J. Dai, Nat. Nanotechnol., 2008, 3, 216.

3 (a) D. Tasis, N. Tagmatarchis, N. Bianco and M. Prato, Chem. Rev., 2006, 106, 1105; (b) X. Peng and S. S. Wong, Adv. Mater., 2009, 21, 625 and references cited therein.

4 (a) A. Star, D. W. Steuerman, J. R. Heath and F. Stodart, Angew. Chem., Int. Ed., 2002, 41, 2508; (b) T. Hasegawa, T. Fujisawa, M. Numata, M. Umeda, T. Matsumoto, T. Kimura, S. Okumura, K. Sakurai and S. Shinkai, Chem. Commun., 2004, 2150; (c) H. Wang, L. Gu, Y. Lin, F. Lu, M. Meziani, P. G. Luo, W. Wang, L. Cao and Y. P. Sun, J. Am. Chem. Soc., 2006, 128, 13364; (d) P. Wu, X. Chen, N. Hu, U. C. Tam, O. Blixt, A. Zettl and C. R. Bertozzi, Angew. Chem., Int. Ed., 2008, 47, 5022.

5 M. Mamen, S. K. Choi and G. M. Whiteseides, Angew. Chem., Int. Ed., 1998, 37, 2754

6 (a) Y. C. Lee and R. T. Lee, Acc. Chem. Res., 1995, 28, 321; (b) C. R. Bertozzi and L. L. Kiessling, Science, 2001, 291, 2357; (c) J. Rojo, V. Diáz, J. M. de la Fuente, I. Segura, A. G. Barrientos, H. H. Riese, A. Bernard and S. Penadés, ChemBioChem, 2004, 5, 291.

7 (a) C. Richard, F. Balavoine, P. Schultz, T. W. Ebbesen and C. Mioskowski, Science, 2003, 300, 775; (b) C. Thauvin, S. Rickling, P. Schultz, H. Celia, S. Meunier and C. Mioskowski, Nat. Nanotechnol., 2008, 3, 743; (c) M. Assali, M. P. Leal, I. Fernández, R. Baati, C. Mioskowski and N. Khiar, Soft Matter, 2009, 5, 948.

8 (a) M. J. O'Connell, P. Boul, C. Ericson, C. Huffman, E. Wang, C. Haroz, J. Kuper, K. D. Tour, L. M. Ausman and R. E. Smalley, Chem. Phys. Lett., 2001, 342, 265; (b) K. Yurekli, C. A. Mitchell and R. Krishnamoorti, J. Am. Chem. Soc., 2004, 126, 9902; (c) Y. Wu, J. S. Hudson, Q. Lu, J. M. Moore, A. S. Mount, A. M. Rao, E. Alexov and P. C. Ke, J. Phys. Chem. B, 2006, 110, 2475.

9 (a) D. H. Charych, J. O. Nagy, W. Spevak and M. D. Bednarski, Science, 1993, 261, 585; (b) D. J. Ahn and J.-M. Kim, Acc. Chem. Res., 2008, 41, 805 and references therein.

10 M. Corti, L. Cantù, P. Brocca and E. Del Favero, Curr. Opin. Colloid Interface Sci., 2007, 12, 148.

11 P. M. Ajayan, Chem. Rev., 1999, 99, 1787.

12 E. J. Wallace and M. S. P. Sansom, Nano Lett., 2007, 7, 1923 and references therein.

13 (a) K. Yurekli, C. A. Mitchell and R. Krishnamoorti, J. Am. Chem. Soc., 2004, 126, 9902; (b) M. J. O'Connell, P. Boul, C. Ericson, C. Huffman, E. Wang, C. Haroz, J. Kuper, K. D. Tour, L. M. Ausman and R. E. Smalley, Chem. Phys. Lett., 2001, 342, 265; (c) L. Vaisman, H. D. Wagner and G. Marom, Adv. Colloid Interface Sci., 2006, 128-130, 37 and references cited therein.

14 For other glyconanorings based on pseudorotaxanes-like complexes using cyclodextrins see: $(a)$ T. Ooya, M. Eguchi and N. Yui, J. Am. Chem. Soc., 2003, 125, 1140; (b) A. Nelson, J. M. Belitsky, S. Vidal, C. S. Joiner, L. G. Baum and J. Stoddart, J. Am. Chem. Soc., 2004, 126, 11914.

15 (a) S. A. Lasky, Annu. Rev. Biochem., 1995, 64, 113; (b) R. Banerjee, K. Das, R. Ravishankar, K. Suguna, A. Surolia and A. M. Vijayan, J. Mol. Biol., 1996, 259, 281.

16 S. Dev and A. Surolia, J. Biosci., 2006, 31, 551. 